\title{
ARTIGO CIENTÍFICO: SUPERESTRUTURA E ARGUMENTATIVIDADE ${ }^{1}$
}

\author{
SCIENTIFIC ARTICLE: SUPERSTRUCTURE AND ARGUMENTATIVITY
}

Valdete A. Borges Andrade

UFU

Viviane Raposo Pimenta

UnB/ UFMG

Walkiria França Vieira e Teixeira

UNESP

RESUMO: Este artigo tem como objetivo verificar a superestrutura do gênero artigo científico, os recursos argumentativos utilizados na sua constituição discursiva, assim como a sua relevância e implicações enquanto texto de divulgação científica. Para a investigação tomamos como base teórica Bakhtin (1979; 1988) e sua definição de gênero do discurso; em relação ao gênero artigo científico buscamos em Van Dijk (1983 apud TRAVAGLIA, 1991), Marconi e Lakatos (1982) suporte teórico relacionado à sua superestrutura; e em Cameron et al (1992) algumas considerações relacionadas ao posicionamento teórico-metodológico de autores dessa categoria de texto, como esses posicionamentos são marcados linguisticamente no texto, e as suas implicações no âmbito acadêmico. Apresentamos, com base nos postulados teóricos adotados, uma proposta de superestrutura do gênero artigo científico e fazemos uma breve análise de corpus sobre a modalização em artigos científicos da área da Linguística.

PALAVRAS-CHAVE: Artigo científico; superestrutura; modalização

ABSTRACT: This article aims to present the superstructure of the genre research paper, the argumentative resources used in its discursive constitution as well as its relevance and implications as a scientific text. As for the research, we have taken, as a theoretical basis, Bakhtin $(1979 ; 1988)$ and his definition of genre of discourse; concerning to the research paper genre we have in Van Dijk (1983 apud TRAVAGLIA, 1991), Marconi and Lakatos (1982) the theoretical support related to its superstructure; and we have in Cameron et al (1992) the considerations regarding the theoretical and methodological assumptions taken by the authors of this text category, as these assumptions are marked linguistically in the text, and its implications in the academic realm. We present based on the theoretical postulates adopted a proposal for a superstructure of the genre research paper and also make a brief corpus analysis on the aspect of modalization present in research papers in the field of Linguistics.

KEYWORDS: Research article; superstructure; modalization

\footnotetext{
${ }^{1}$ Este artigo é um desdobramento de parte da dissertação de mestrado "Modalidades em artigos científicos da área da linguística" defendida em 2010 sob a orientação do Prof. Dr. Luiz Carlos Travaglia, e da dissertação intitulada "Textos forenses: um estudo de seus gêneros textuais e a sua relevância para o gênero sentença” (2007), também orientada pelo Prof. Dr. Luiz Carlos Travaglia.
} 


\section{Revista do SELL}

V. $4, n^{\circ} .1$

ISSN: $1983-3873$

\section{INTRODUÇÃO}

Neste trabalho, define-se o gênero artigo científico na perspectiva dos textos de divulgação científica e, a partir da discussão sobre esses textos, caracteriza-se, brevemente, na perspectiva bakhtiniana, o gênero do discurso. Entendendo o processo de apropriação dos gêneros como um aspecto importante das práticas sociais. Para Bakhtin "a utilização da língua efetua-se em forma de enunciados (orais e escritos), concretos e únicos, que emanam dos integrantes duma ou doutra esfera da atividade humana, o enunciado reflete as condições específicas e as finalidades de cada uma dessas esferas." (BAKHTIN, 1988, p. 79).

Os gêneros do discurso de divulgação científica inserem-se no campo de investigação dos discursos dominantes, chamados por Hamilton (1998) de "institucionalizados". A autora os distingue dos discursos locais "vernaculares", no entanto, não os entende como categorias independentes ou radicalmente separadas, mas interligadas, pois para a autora os discursos dominantes estão associados a organizações formais. Tratam-se de discursos especializados incluídos em comunidades discursivas de práticas padronizadas e definidos em termos dos propósitos formais da instituição à qual estão ligados. Esses textos preveem agentes (cientistas, pesquisadores, professores, autores de Livros Didáticos, especialistas) que, em relação ao conhecimento, são valorizados legal e culturalmente, assim, são poderosos na proporção do poder da instituição de origem.

O ensaio, em segunda parte, traz um estudo teórico do texto, do discurso e do gênero textual discursivo e a sua argumentatividade, e analisa a superestrutura do artigo científico, para depois, propor uma superestrutura ${ }^{2}$ que acreditamos poder ser considerarada pertinente para o estudo, dando destaque aos critérios mínimos exigidos pelo meio acadêmico. De acordo com Van Dijk (1983) a superestrutura do gênero artigo científico pode apresentar uma variação especial das superestruturas argumentativas, consistindo de uma justificativa, da colocação de um problema e uma solução, além de uma conclusão. Assim, conforme Van Dijk (1983), os discursos científicos podem se

\footnotetext{
${ }^{2}$ Trata-se de proposta de superestrutura que pode orientar a sua organização em termos de estrutura composicional e estilo, pois, assim como os protótipos didáticos, possui estruturas flexíveis e vazadas que permitem modificações por parte daqueles que queiram utilizá-la com outros enfoques teóricometodológicos que não o da proposta inicial, e que atenderá aos propósitos comunicativos de cada autor, bem como o de suas filiações teóricas.
} 


\section{Revista do SELL \\ v. $4, \mathrm{n}^{\circ} .1$ \\ ISSN: $1983-3873$}

apresentar diferentes em áreas específicas, e sua estrutura global pode claramente ser modificada.

Com base nesses estudos, propomos uma superestrutura que consideramos pertinente para diferentes áreas, uma vez que na maioria dos artigos científicos se é exigido minimamente tais categorias: 1) Resumo; 2) Palavras-chave; 3) Introdução; 4) Desenvolvimento; 5) Considerações finais/conclusão.

Acreditamos que esse trabalho irá contribuir com os estudos da Linguística Textual bem como para os estudos sobre texto e discurso, pois nos permite verificar a importância de se conhecer a superestrutura do gênero artigo científico e sua correlação com a argumentação, e afirmar que a argumentação, inerente ao ato de linguagem, está correlacionada com a superestrutura do gênero em questão.

Para este fim, apresentamos primeiramente algumas considerações sobre texto e discurso, e gêneros do discurso. Discutimos a superestrutura do artigo científico, apresentamos uma proposta de superestrutura, e analisamos alguns exemplos de modalização presentes em artigos científicos. Finalmente, fazemos algumas considerações sobre o tema haja vista que, em se tratando de língua e linguagem, nada é fixo e definitivo, pois tratam-se de categorias dinâmicas e flexíveis que têm em seus usuários seus principais agentes modificadores. Quanto à análise dos exemplos nos quais evidenciamos a modalização por meio de marcas linguísticas em artigos científicos da área da Linguística, utilizamos o método de análise de corpus de cunho qualitativo. Para nortear a discussão, optamos pelo método dialético, mais especificamente a dialética da complementaridade, por tratar-se de um tema cujo objeto - a lingua(gem) - apresenta pontos e contrapontos que não podem ser desconsiderados.

\section{Algumas considerações sobre texto, discurso e gêneros textuais/discursivos}

Na área dos estudos sobre texto e discurso, existem diversas concepções de texto, o que faz com que se estabeleça certa confusão entre os conceitos de texto e de discurso. Neste artigo consideramos esses dois termos como diferentes, mas indissociáveis quando se tenta explicar os fenômenos linguísticos. Achamos pertinente esclarecer, primeiramente, o que entendemos por discurso para depois explicitar como será concebido nosso objeto de estudo, o texto.

Assim como Travaglia chamamos de discurso 


\section{Revista do SELL \\ v. $4, \mathrm{n}^{\circ} .1$ \\ ISSN: $1983-3873$}

toda atividade comunicativa de um locutor, numa situação de comunicação determinada, englobando não só o conjunto de enunciados por ele produzidos em tal situação - ou os seus e os de seu interlocutor, no caso do diálogo - como também o evento de sua enunciação (TRAVAGLIA, 2006, p. 67).

Ou seja, o discurso é uma atividade comunicativa em que tanto enunciador como enunciatário se veem envolvidos numa situação de interação, regulada por um contexto sócio-histórico e ideológico.

Partindo do fato de que nosso objeto de estudo será o texto, definiremos, então, o que, para fins deste estudo, entendemos por texto. Para tal, utilizaremos colocações advindas da Semiótica, com Barros (2007), e da Linguística Textual, com Koch (1996).

De acordo com Barros, "um texto define-se de duas formas que se complementam: pela organização ou estruturação que faz dele um "todo de sentido", como objeto da comunicação que se estabelece entre um destinador e um destinatário." (BARROS, 2007, p.7). "A primeira definição, objeto de organização ou estruturação, refere-se ao estudo interno do texto, ou seja, seus mecanismos linguísticos e sua estruturação". (ANDRADE, 2012, p. 34).

A referida autora, ao definir texto como objeto de comunicação, estabelece a relação entre o exame interno do texto e seu contexto sócio-histórico. Estas duas definições se inter-relacionam, pois ao analisar o texto buscam-se marcas ou pistas tanto internas quanto externas que Ihe atribuem sentido. Nesta perspectiva, o estudo do texto pode ser concebido como objeto de significação (análise interna do texto), e como objeto de comunicação (análise externa do texto).

Por outro lado, Koch não só conceitua texto, mas também estabelece a relação entre texto e discurso:

Pode-se tomá-lo em duas acepções: em sentido lato, para designar toda e qualquer manifestação da capacidade textual do ser humano, quer se trate de um romance ou poema, quer de uma música, uma pintura, um filme, uma escultura, etc., isto é, de qualquer tipo de comunicação realizada através de um sistema de signos. Em se tratando de linguagem verbal, tem-se o discurso [...] (KOCH, 1996, p. 21).

Segundo Koch (1996), o discurso é considerado como uma atividade comunicativa de um locutor, em uma determinada situação, englobando o conjunto de enunciados produzidos por ele e por seu interlocutor. Entretanto, para produzir comunicação, o 


\section{Revista do SELL \\ v. $4, \mathrm{n}^{\circ} .1$ \\ ISSN: $1983-3873$}

discurso deve ser bem estruturado e compreensível na sua materialidade linguística, o texto.

Nessa perspectiva, Koch aborda o conceito de texto como qualquer unidade linguística que concretiza a intenção do falante e o conceito de discurso como uma atividade em que o locutor organiza uma unidade de sentido para assim comunicá-la. Observa-se que a autora se preocupa com os mecanismos de funcionamento textual, com sua estrutura interna, ou seja, com a relação estabelecida entre os enunciados e a sua tessitura, e defende a posição de que o texto não é tido como uma estrutura pronta, mas que é concebido como um processo que está em constante construção. Ou melhor, o texto é considerado como uma produção verbal com diferentes fins sociais, como uma atividade intencional e interacional do falante.

De acordo com Travaglia, o texto é

entendido como uma unidade concreta (perceptível pela visão ou audição), que é tomada pelos usuários da língua em uma situação de interação comunicativa específica, como uma unidade de sentido e como preenchendo uma função/intenção comunicativa reconhecível e reconhecida, independentemente de sua extensão. (TRAVAGLIA, 1991, p. 24).

Assim, nesse estudo, concebemos o texto como uma unidade linguística concreta em permanente construção, a qual é tomada pelos usuários com a função de comunicação e de interação, sem levar em consideração seu tamanho.

Em relação aos gêneros textuais discursivos, a posição de Kress (1993) e Fairclough e Chouliarki (1999) é a de que os gêneros bem construídos, por parte de grupos dominantes, como forma de poder e pressão nos vários segmentos da sociedade, poderiam permitir o acesso a benefícios culturais, econômicos e sociais o que está diretamente ligado à capacidade de ler e escrever, ao desenvolvimento da habilidade da escrita.

Kress (1993) aborda o gênero não com foco na tarefa que está sendo feita através do texto, mas sim enfocando os fatores estruturais da ocasião social específica em que o texto está sendo produzido. Para ele são esses fatores que dão origem às configurações das características linguísticas que aparecem no texto, e que representam as realizações ou os reflexos das estruturas das relações sociais. Kress (1993) vê o gênero como um evento social que só se materializa linguisticamente por meio do texto. 


\section{Revista do SELL \\ V. $4, n^{\circ} .1$}

ISSN: $1983-3873$

Assim, tais postulados reforçam a função social da linguagem, através dos gêneros, que são para Fairclough (1992) usos da linguagem associados a tipos de atividades ratificadas com aspectos convencionais. Esses gêneros são expressos em forma de discurso, que, por sua vez, são manifestações da linguagem por meio de textos.

Bathia (1994) advoga que membros especialistas de qualquer comunidade discursiva normalmente devem ter não só o conhecimento de sua área específica, mas também o da estrutura dos gêneros que utilizam em seus textos. Assim, segundo o autor, seus textos ganham um caráter de estrutura textual interna convencionalizado.

O autor cita ainda, que embora o autor do texto tenha liberdade para usar os recursos linguísticos da melhor forma que lhe convém, ele deve atender a certos padrões que limitam e estabelecem certas formas de melhor desenvolver os gêneros textuais por ele redigidos. Para Bathia (1994), o autor pode utilizar as regras e convenções de um gênero para alcançar seus objetivos comunicativos e intenções particulares, no entanto, ele não pode deixar tais regras e convenções totalmente; pois, assim corre o risco de redigir algo totalmente absurdo segundo suas intenções de interação e comunicação social.

Segundo Bathia (1994) existem restrições ao operacionalizar uma intenção, posicionar e estruturar um gênero em um texto específico e isto, provavelmente, seja o motivo de muitos tenderem a estruturar gêneros particulares de forma mais ou menos idêntica. Os membros de uma determinada comunidade discursiva possuem um conhecimento sobre os gêneros textuais a serem utilizados que os ditos "leigos" naquele específico tema não possuem.

\section{2. $O$ texto de divulgação científica}

Moita-Lopes \& Rojo (2004) afirmam que

é preciso considerar sobre o fato de que a linguagem não ocorre em um vácuo social e que, portanto, os textos não têm sentido em si mesmos, mas interlocutores situados no mundo social com seus valores, projetos políticos, histórias e desejos constroem seus significados para agir na vida social, ou seja, os significados são contextualizados, essa compreensão nos possibilita situar os discursos a que somos expostos e recuperar sua situacionalidade social ou seu contexto de produção e interpretação: quem escreveu, com que propósito, onde foi publicado, quando, quem era o interlocutor projetado etc. Esta teorização terá uma implicação prática em relação aos artigos científicos, pois possibilita uma visão de linguagem que fornece artifícios para se fazer escolhas éticas entre os discursos de 


\section{Revista do SELL \\ V. $4, n^{\circ} .1$}

ISSN: $1983-3873$

divulgação científica pelos quais circulamos e utilizamos. (MOITA-LOPES \& ROJO, 2004, p. 37-38)

De acordo com Rojo (2008, p. 2) "a ciência foi um dos bens culturais, assim como as artes e os ofícios, que entraram na disputa social como bens cobiçados a partir do final da Idade Média". Esta disputa se deve a várias ordens de razão como, mudanças sociohistóricas, interesse na qualificação dos trabalhadores, mudança na dinâmica da política e nas classes dominantes.

Para Rojo (2008),

a própria ideia de DI-VULGAÇÃO, isto é, a ação de dar ao vulgo - à plebe, aos pobres, aos trabalhadores, aos que falam a língua vulgar, ou seja, ao povo - os bens do conhecimento, nasce desse movimento de acesso das massas aos bens culturais valorizados. Assim, a divulgação foi patronizada pelos intelectuais da Revolução Francesa, os iluministas, que devem levar as luzes da ciência ao século XVIII. (ROJO, 2008, p. 2)

Rojo (2008, p. 2) atesta que "os textos e discursos de divulgação científica surgem, então, dessa vontade política de 'dar ao vulgo' os bens culturais da ciência do conhecimento". Para a autora

esses bens culturais foram disputados pelos homens livres, pelos padres da Igreja, pela burguesia, pelos iluministas e pelos trabalhadores. De modo que, ao final da chamada Idade Moderna, já tínhamos em boa parte do Ocidente uma situação em que todas as classes têm acesso à escolarização para que pudessem ter acesso aos bens culturais da ciência. A escolarização nasce, então, inclusive como mecanismo de disciplina(riza)cão dos 'bárbaros' por meio dos textos científicos selecionados para compor os currículos. (ROJO, 2008, p. 3)

Rojo (2008) ainda assevera que podemos distinguir três esferas de produção principais para os textos da ciência:

a) os discursos primários, isto é, aqueles que os cientistas escrevem para seus colegas e que falam sem reservas a linguagem das ciências, publicados nas revistas especializadas e falados nas conferências;

b) os discursos de divulgação científica, com diferentes níveis de especialização, destinados a leitores mais ou menos especializados, escritos por cientistas com a intenção de atingir público mais amplo, ou por jornalistas especializados em jornalismo científico;

c) os discursos didáticos, que mais que divulgar achados científicos, destinam-se a ensinar os alunos certos conteúdos científicos; são escritos, em geral, por professores e seu leitor-modelo é um estudante; por isso, o texto inclui um número maior de explicações, além de exercícios para assimilação, revisão, avaliação. (ROJO, 2008, p. 594). 


\section{Revista do SELL}

v. $4, \mathrm{n}^{\circ} .1$

ISSN: $1983-3873$

Quanto à marca de autoria presente nas marcas linguísticas do texto, esta apontará as correntes teóricas às quais 0 autor se filia. Assim, alguns autores contemporâneos têm dado ênfase à utilização da primeira pessoa do singular para se dirigirem aos seus interlocutores, pois, para esses autores, quem fala é o "eu" concreto e não um "eu" abstrato, pretensamente objetivo, que profere verdades impessoais. Para ilustrar, tomamos emprestadas algumas das palavras com que Descartes iniciou o discurso filosófico da modernidade: "não proponho este escrito senão como uma história, ou, se o preferirdes, como uma fábula." (DESCARTES, 1985, p.8).

Sobre a posição tomada pelos autores dos artigos científicos em relação ao seu objeto, para Cameron et al (1992), sobre o ato de fazer pesquisa e as consequências éticas das escolhas envolvidas, dizem os autores que os pesquisadores, antes de mais nada, são pessoas posicionadas socialmente, e assim, trazem, inevitavelmente, seus pensamentos e tudo o que constitui a sua subjetividade para dentro dos processos de pesquisa com os quais se envolvem. No entanto, segundo os mesmos autores, essa subjetividade não deve ser vista como algo negativo, mas como "um elemento presente nas interações humanas que incluem o objeto de estudo."3 (CAMERON et al, 1992, p.5)

\section{A superestrutura do gênero artigo científico}

Para Marconi e Lakatos (1982), exige-se sempre a mesma estrutura nos artigos científicos: introdução, desenvolvimento e conclusão, que é basicamente a superestrutura de quase qualquer texto dissertativo. O uso dessa padronização ajuda em uma possível avaliação, pois o autor, ao utilizá-la, dá indícios de que teve um cuidado especial ao "construir" o texto e uma maior preocupação com o conteúdo. Sobre essa estrutura Castro (1976) esclarece:

a) Introdução ${ }^{4}$. O autor deve informar o assunto que irá tratar, o objetivo e a metodologia para que o leitor tenha uma visão clara daquilo que se pretende desenvolver na pesquisa. O autor precisa ter em mente alguns pontos que devem ser considerados: (a) Importância do assunto ou do tópico, cabendo

\footnotetext{
${ }^{3}$ Tradução nossa para o seguinte trecho: "Our view is that the subjectivity of the observer should not be seen as a regrettable disturbance but as one element in the human interactions that comprise our object of study."

4 Alguns autores, por questão de estilo e escolhas teórico-metodológicas, têm optado por utilizarem "Considerações Iniciais".
} 


\section{Revista do SELL}

v. $4, n^{\circ} .1$

ISSN: $1983-3873$

ao autor avaliar a importância daquilo que ele pretende pesquisar (justificativa) (b) O que se sabe sobre o assunto. Deve-se investigar o que já foi publicado sobre o assunto. Esse tipo de pesquisa é frequentemente chamada de "revisão da literatura".

b) Desenvolvimento. Refere-se à exposição de um problema, de uma dúvida ou de uma curiosidade. Nesta parte do artigo, a análise dos dados deve ser verdadeira, ou seja, é necessário que o autor demonstre a veracidade dos dados analisados.

c) Conclusão ${ }^{5}$. A conclusão é a retomada do que foi apresentado de maneira ampla na introdução e é também o momento da avaliação dos resultados da pesquisa. Na realidade, o que se busca nesse item é expor as contribuições mais relevantes da pesquisa, bem como seus pontos fracos e a possibilidade, por parte do leitor, de ampliar a pesquisa. "Uma pesquisa abre novas perspectivas, sugere áreas em que nosso conhecimento é precário e abala convicções antigas; tais implicações devem ser exploradas no capítulo de conclusões." (CASTRO, 1976, p.12).

Já Van Dijk (1983) assevera que a superestrutura do gênero artigo científico apresenta uma variante especial das superestruturas argumentativas. Para ele, a estrutura básica do artigo científico consiste em uma conclusão e sua justificativa, como também a colocação de um problema e uma solução. Segundo Van Dijk,

En los discursos científicos se presenta uma variante especial de las superestructuras argumentativas, de las que aqui daremos um breve ejemplo. La estructura básica del discurso científico no (sólo) consiste em uma CONCLUSION y su JUSTIFICACION, sino también em um PLANTEO DEL PROBLEMA y una SOLUCION (VAN DIJK, 1983, p. 164).

Para Van Dijk (1983), os discursos científicos se apresentam bem diferentes em outras disciplinas, e sua estrutura global pode ser claramente modificada. Entretanto, a aceitabilidade da publicação vai depender de uma série de critérios que exigem métodos e comunicação adequados. Ou seja, para ele não é necessário que um artigo tenha um esquema canônico como o de Castro (1976). Com que concordamos, embora artigos científicos de diferentes áreas tenham alguns requisitos básicos.

\footnotetext{
5 Também chamada de "Considerações Finais" dependendo da filiação teórica e escolhas teórico-
} metodológicas do autor. 


\section{Revista do SELL}

v. $4, \mathrm{n}^{\circ} .1$

ISSN: $1983-3873$

\subsection{Proposta de superestrutura do artigo científico ${ }^{6}$}

A seguir apresentamos uma superestrutura com base nos autores estudados, uma vez que na maioria dos artigos científicos se é exigido minimamente tais categorias:

a) Resumo: breve exposição do texto, em que apenas os aspectos mais relevantes são apresentados. Essa parte do artigo deve vir em Português e em uma língua estrangeira;

b) Palavras-chave: são palavras específicas que têm o propósito de deixar claro qual é o assunto tratado, ou seja, os pontos básicos que são tratados no artigo. Também deve vir em Português e em uma língua estrangeira;

c) Introdução ${ }^{7}$ : refere-se à apresentação dos objetivos, do corpus, da metodologia, das hipóteses, das partes do texto e do que trata cada uma;

d) Desenvolvimento: parte do texto em que se apresentam as análises, as propostas e uma sustentação para elas. Nesta parte do artigo parece acontecer mais especificamente a argumentação;

e) Considerações finais/conclusão: em que geralmente se faz um balanço do que foi conseguido. Às vezes, é a parte do artigo em que se apontam as falhas do estudo, o que constitui uma estratégia argumentativa. Na verdade, ao mostrar que falta algo, o autor está dando credibilidade para o trabalho dele, quer dizer, ele mostra que seu artigo é confiável, digno de credibilidade. Além disso, podem aparecer perspectivas de continuidade dos estudos.

\subsection{Artigo científico: superestrutura, argumetatividade e modalização}

Este trabalho permitiu-nos refletir sobre o uso das modalidades como recursos linguísticos em seu funcionamento discursivo, e verificar quais as funções que esses

\footnotetext{
${ }^{6}$ Esta proposta foi elaborada por Andrade (2010) em sua dissertação de mestrado "Modalização em artigos científicos da área da Linguística".

${ }^{7}$ Ou Considerações Iniciais. Conforme apontamentos já registrados relacionados ao posicionamento do autor e escolhas teórico-metodológicas.
} 


\section{Revista do SELL \\ v. $4, \mathrm{n}^{\circ} .1$ \\ ISSN: $1983-3873$}

recursos desempenham em diferentes partes da superestrutura do gênero artigo científico.

As modalidades, as marcas de intenção, os operadores argumentativos, as pressuposições são marcas linguísticas argumentativas utilizadas pelo locutor para persuadir/convencer seu auditório a aceitar os argumentos apresentados e aderir a uma tese (ideia ou proposta de ação). Sem a utilização dessas marcas linguísticas a argumentação não se estabelece de maneira eficaz.

Partindo do pressuposto de que a manifestação das modalidades pode acontecer por meio de diferentes recursos linguísticos, nossa análise considera esses diferentes recursos, marcados pelos verbos, advérbios, substantivos, auxiliares modais, expressões cristalizadas, verbos atitudinais..., e também a manifestação dos mesmos itens lexicais sendo utilizados para fins distintos.

Como exemplo de um mesmo item lexical utilizado com funções diferentes, apresentamos algumas possibilidades do uso do verbo poder estudadas por Koch (1996, p. 74):

(01) Paulo pode levantar este embrulho sem esforço. (certeza da possibilidade)

(02) Paulo pode ir ao cinema hoje, eu lhe dei minha permissão. (permissibilidade)

(03) Cuidado, esta jarra pode cair! (possibilidade)

(04) Os inimigos podiam ser uns cem. (probabilidade)

(05) O pai pode castigar os filhos desobedientes. (permissibilidade)

Vejamos dois exemplos, retirados do nosso corpus, de um mesmo item lexical que estabelece dentro do texto uma função, quando há outra que poderia ocorrer:

(06) Partindo do princípio de que um dicionário de língua deve ser avaliado a partir de sua concepção teórica, entendendo-se esta como uma teoria gramatical, uma das tarefas enfrentadas pelo dicionarista é como organizar verbetes de palavras gramaticais. (BORBA, 2007, p. 137) (Introdução - do que se trata a pesquisa)

Na proposição acima, temos o verbo dever (auxiliar modal) + ser (infinitivo) que, normalmente, é empregado como uma modalidade deôntica ( $\mathrm{O}$ aluno deve comparecer a $75 \%$ das aulas/ obrigatoriedade), entretanto está sendo usado com a modalidade de necessidade (modalidade alética). Vale esclarecer que neste estudo levamos em 


\section{Revista do SELL}

v. $4, \mathrm{n}^{\circ} .1$

ISSN: $1983-3873$

consideração a manifestação dos mesmos itens lexicais sendo utilizados para desempenhar outras funções.

Apesar do grande número de ocorrências de algumas modalidades, estas assumem diferentes funções em diferentes partes do artigo científico. Por exemplo, quando o autor na introdução fala do que se trata a pesquisa, apresenta os objetivos, o corpus, a metodologia e as hipóteses; no desenvolvimento quando apresenta os dados, propõe a análise... as modalidades epistêmicas predominam, entretanto a função que elas estabelecem em cada um desses movimentos (ação do autor) é diferente. Por exemplo:

(07) Da mesma forma, e inspirada nessa perspectiva, defendo que os "prefácios do professor" contidos nos livros didáticos constituem um espaço e um discurso que contribuem também como um "documento de identidade" do professor, além de tantos outros territórios discursivos nos quais esse sujeito se move e se molda (GRIGOLETTO, 2003, p. 76).

(introdução: movimento - do que se trata a pesquisa)

(modalidade epistêmica de certeza/ recurso: presente do indicativo/ função: defender uma ideia)

(08) Como dificilmente dois leitores tomarão exatamente as mesmas decisões e seguirão os mesmos caminhos, jamais haverá leituras exatamente iguais [...] (KOCH, 2007, p. 30).

(desenvolvimento: movimento - proposta da análise)

(modalidade epistêmica de certeza/ recurso: advérbio/ função: enfatizar uma ideia)

Podemos verificar no exemplo (07) que a função da modalidade epistêmica de certeza, na parte da apresentação da pesquisa, é defender uma ideia; já no enunciado (08), que faz parte do movimento: proposta da análise, a função dessa mesma modalidade é outra, enfatizar uma ideia com o auxílio dos advérbios. Observe-se também que em cada um desses enunciados utilizou-se diferentes recursos para a mesma modalidade:

- Exemplo (07): inspirada, defendo, contribuem, se move e se molda/ recurso: presente do indicativo;

- Exemplo (08): tomarão: futuro do presente/ dificilmente, exatamente, jamais/ recurso: advérbio.

Em outro exemplo, temos: 


\section{Revista do SELL \\ v. $4, \mathrm{n}^{\circ} .1$ \\ ISSN: $1983-3873$}

(09) Trata-se, no caso, de uma alteridade multilinearizada, fragmentada, descorporalizada, volatilizada, mas fundada em nossos saberes, nossas relações com o mundo e nossa interação em cada cultura. $(\mathrm{KOCH}, 2007$, p, 35).

Por meio das marcas de impessoalidade o produtor manifesta a certeza de um saber com a intenção de fazer com que o leitor aceite seu argumento como verdadeiro sem se comprometer explicitamente, e também sem alternar as modalidades que ficam entre 0 crer e o saber.

Essas marcas de impessoalização trazem fatos interessantes ao uso da modalidade epistêmica da certeza para a argumentação, mas é importante ressaltar que, neste caso, o recurso modalizador é o presente do indicativo. Na certeza marcada com o presente do indicativo incluem-se também: a) os casos dos conectores adversativos; b) os casos com expressões reformulativas; e c) os casos com argumentos de autoridade.

\section{Considerações Finais}

Partindo da teoria bakhtiniana sobre o gênero, observamos que os gêneros são formas de dizer, situadas e contextualizadas, existentes na sociedade. Essas formas de dizer e de criar sentidos - desenvolver temas - são cristalizadas historicamente pelo funcionamento de certos campos ou esferas sociais - no caso do artigo de divulgação científica, a esfera científica - que formatam e regularizam, mas de maneira flexível, temas que podem ser abordados, formas ou organizações dos textos esperados, estilos admitidos - variedades linguísticas, jargões etc.

Assim, sendo o gênero (e o texto que a ele pertence) fruto de um contexto ou situação específicos, ele é, por um lado, flexível, pois se adapta às diversas situações; por outro, é estável de maneira a satisfazer as maneiras de dizer em um dado campo ou esfera social. Neste sentido, podemos dizer que os gêneros são, pois, legião. E sendo tantos e tão diversos, exigem diferentes capacidades para sua compreensão e produção.

$\mathrm{Na}$ perspectiva de Bakhtin é o tema que deve ser apreendido, a ele é que devemos agir responsivamente, pois todo o resto, forma de composição e estilo, está a serviço de fazer ecoar um tema. Logo, é o tema que deve ecoar no artigo de divulgação científica.

Como vimos, para realizar os movimentos propostos por Swales e Feak (1994) em relação à estrutura composicional do artigo científico, devemos levar em consideração a 


\section{Revista do SELL \\ v. $4, \mathrm{n}^{\circ} .1$ \\ ISSN: $1983-3873$}

situação de produção deste texto, ou seja, os propósitos de cada um para enunciar. Quanto ao estilo, às escolhas linguísticas que fazemos para dizer o que queremos dizer, para gerar o sentido desejado - escolhas de léxico, de estrutura frasal, estrutura morfossintática (adjetivo ao invés de substantivo), de escolha do registro linguístico etc. devemos ressaltar que nenhuma escolha é inocente.

Assim, considerando que estilo e forma composicional estão sempre a serviço do tema, apresentamos neste breve ensaio, a forma composicional, a forma de organização e acabamento do artigo científico, sua superestrutura conforme proposto por Van Djik, formas relativamente estáveis de progressão temática deste gênero específico. De acordo com Aranha (2007, p. 10) "dela dependerá ou não que este seja aceito para publicação pelos editores e também pela comunidade de leitores, além de poder ser citado por outros pesquisadores".

Ressaltamos que este diálogo estabelecido com a teoria bakhtiniana não deve ser desvinculado de uma teoria da prática social, da maneira como os atores sociais demonstram estrategicamente sua adesão aos valores de sua comunidade discursiva, do fato de que o texto apresenta-se a si mesmo como um discurso autorizado por atores sociais legitimados e específicos que vincula as unidades textuais a estruturas dominantes, e que essas exercem uma real influência sobre as formas linguísticas por meio das quais os gêneros são realizados.

Finalmente, ressaltamos a questão da atualidade e da incompletude do gênero, pois a realidade histórica dos signos é produzida a partir da avaliação social do discurso, e a prática, enquanto atividade inscrita no tempo, é sempre não acabada, no sentido de que permanece incompleta e emergente, o que nos permite dizer, conforme Hanks (2008), que os gêneros devem ser concebidos como recursos esquemáticos e incompletos com os quais os falantes necessariamente improvisam no curso das práticas.

\section{REFERÊNCIAS}

ANDRADE, V. A. B. 2010. 150 f. Modalização em artigos científicos da área da Linguística. Dissertação (Mestrado em Linguística Textual) -Instituto de Letras e Linguística, Universidade Federal de Uberlândia, Uberlândia, 2010.

BAKHTIN, M. Estética da criação verbal. Trad. Maria Ermantina Galvão G. Pereira. São Paulo: Martins Fontes, 1979. 
, O discurso no romance. In: Questões de literatura e de estética: a teoria do romance. São Paulo: Hucitec, 1988 [1935]. p. 71-210.

BARROS, D. L. P. Teoria Semiótica do Texto. São Paulo: Ática, 2007.

BATHIA, V.K. Analysing genre: language use in professional settings. London: Longman, 1994.

CAMERON, D. et al. Researching language: issues of power and method. London: Routledge, 1992.

CASTRO, C. M. Estrutura e apresentação de publicações científicas. São Paulo: McGraw-Hill do Brasil, 1976.

FAIRCLOUGH, N. Analysing discourse: textual analysis for social research. London: Routledge, 1992, p.37-51.

,and CHOULIARAKI, L. discourse in late modernity: rethinking critical discourse analysis. Edinburg: Edinburg University Press, 1999.

HAMILTON, M. Local literacies: reading and writing in one community. London: Routledge, 1998.

KOCH, I. G. V. O texto e a construção dos sentidos. São Paulo: Cortez, 1997.

Argumentação e Linguagem. São Paulo: Cortez, 1996.

KRESS, G. Against arbitrariness the social production as a foundational issue. In: Critical discourse analyses: discourse and society. London: Sage, 1993, p. 156-191.

MARCONI, M. A.; LAKATOS, E. M. Técnicas de pesquisa. Brasil: Atlas, 1982.

TRAVAGLIA, Luiz Carlos. Um estudo textual-discursivo do verbo no Português do Brasil. 1991. 195 f. Tese (Doutorado em Linguística) - Instituto de Estudos da Linguagem, Universidade Estadual de Campinas, Campinas, 1991.

Gramática e Interação. São Paulo: Cortez, 2006.

VAN DIJK, T. A. La ciência del texto: um enfoque interdiciplinario. Buenos Aires/Barcelona: Paidós, 1983. p. 141-173.

\section{CORPUS}

BORBA, F. S. A informação gramatical nos dicionários. Alfa, São Paulo, v. 51, n. 1, p. 137-149, 2007. Disponível em: <http://www.alfa.ibilce.unesp.br/normas.php>. Acesso em: 10 jun. 2009.

GRIGOLETTO, M. Documentos de identidade: a construção da posição "sujeito-professor" nos livros didáticos de inglês. Letras \& Letras, Uberlândia, v. 19, n 1, p. 75-88, jan. / jun. 2003. 


\section{Revista do SELL}

v. $4, n^{\circ} .1$

ISSN: 1983-3873

KOCH, I. G. V. Hipertexto e construção do sentido. Alfa, São Paulo, v. 51, n 1, p. 23-28, 2007. Disponível em < http://www.alfa.ibilce.unesp.br/normas.php >. Acesso em: 7 ago. 2009. 